\title{
Identification of a New Race and Development of DNA Markers Associated with Powdery Mildew in Melon
}

\author{
Hoy-Taek Kim ${ }^{1,2}$, Jong-In Park', Arif Hasan Khan Robin', Tomoko Ishikawa², Maki Kuzuya², Manabu Horii², \\ Katsutoshi Yashiro², Ill-Sup Nou* \\ ${ }^{1}$ Department of Horticulture, Sunchon National University, Suncheon 57922, Korea \\ ${ }^{2}$ Plant Biotechnology Institute, Ibaraki Agricultural Center, Kasama 319-0206, Japan
}

\begin{abstract}
Powdery mildew disease caused by an obligatory parasitic fungus Podosphaera xanthii is a serious problem of melon (Cucumis melo L.) production worldwide. Severity of problem is further associated with emergence of new races over the years. In this study a new race of powdery mildew fungus was discovered from Ibaraki, Japan. The race was different from all other existing races of P. xanthii occurring in Japan. Phenotypic and genetic analysis established the new fungus type as a new race, N5. Ten melon lines were infected with a total of eight fungal races including the new N5 race and it was found that all melon lines had different disease reactions against the new race compared to other seven races. Only four melon genotypes were found resistant out of 42 commercial cultivars and lines were tested. Disease reactions of two sets of $\mathrm{F}_{2}$ populations and one set of backcross population revealed that two separate epistatic gene loci located in two different linkage groups (LG), LG II and LG XII, interact together for the resistant or susceptible reaction of melon lines. A total of six simple sequence repeat (SSR) markers were found polymorphic in melon lines out of 16 tested in response to N5 race. Two different sets of $\mathrm{F}_{2}$ populations between resistant and susceptible melon lines were assessed with two polymorphic SSR markers located in two different groups, LG II and LG XII. SSR genotyping yielded $78 \%$ and $94 \%$ expected polymerase chain reaction fragments in favor of resistance or susceptibility of $\mathrm{F}_{2}$ populations of CM17187 $\times$ PMR5 and PMR $45 \times$ PMR5 of melon lines, respectively.
\end{abstract}

Keywords Powdery mildew, Melon, Podosphaera xanthii, Simple sequence repeat markers, Genetic analysis

\section{INTRODUCTION}

Powdery mildew is one of the important diseases in melon (Cucumis melo L.) that commonly occurs in the cultivated fields. The causal agent of this disease, Podosphaera xanthii, is an absolute parasite. Occurrence of this disease was reported in many different countries over the last four decades including Israel (Cohen et al. 1984), United States (McCreight et al. 1987), France (Epinat et al. 1992), Sudan (Mohamed et al. 1995) and Japan (Hosoya et al. 1999). Powdery mildew resistant line PMR45 was reported for the first time in the United States in 1935, but that was found susceptible against a new powdery mildew fungus occurred later. Thus the fungus occurred later was named as race 2 and another fungus not endemic to PMR45 was named as race 1 (Jagger et al.
1938). In 1946, PMR5 and PMR6 with resistance lines against both race 1 and race 2 were bred, but again another new fungus (race 3) occurred against which the PMR5 became susceptible (Pryor et al. 1946). It is clearly evident that break-down of resistance by $P$. xanthii against the resistant melon lines is a recurring phenomenon. McCreight (2006) reported a total of 28 different races of $P$. xanthii that causing powdery mildew of melon worldwide.

In Japan, Hosoya et al. (1999) classified melon powdery mildew fungi into four different classes namely race $1, \mathrm{~N} 1$, $\mathrm{N} 2$, and race 5. The authors collected those fungi from Ibaraki region of Japan and inoculated those races into six selected melon lines (Fuyu3, PMR45, WMR29, Edisto47, PI414723, PMR5) (Hosoya et al. 1999). Later, Kuzuya et al. (2004) reported seven different races of powdery mildew fungi (race 1, 2, 3, 4, 5, 6, 7) tested against eight

Received May 17, 2016; Revised May 21, 2016; Accepted May 25, 2016; Published May 31, 2016

*Corresponding author Ill-Sup Nou, nis@sunchon.ac.kr, Tel: +82-61-750-3249, Fax: +82-61-750-5389 
selected melon lines (Fuyu3, PMR45, WMR29, Edisto47, PI414723, PMR5, MR-1, and PI124112). A few new races identified by Kuzuya et al. (2004) were different from previously reported races by Hosoya et al. (1999). In addition, Izumikawa et al. (2008) reported three new races of powdery mildew fungi (race A, S, O) by using a modified testing method initially developed by Bardin et al. (1999). The authors collected fungi samples from the cultivated melon fields in 2006.

The existing inoculation test for screening out $P$. xanthii resistance is associated with some unstable disease index due to variability created by various environmental or cultural condition and differential growth status of leaf discs. In addition, phenotyping is generally difficult when the resistance is governed by recessive alleles. In such a condition it is difficult to identify the heterozygous state. Screening of a large of number of samples is often required to make a decision.

Since numbers of different races of powdery mildew fungi are available therefore to develop a race-specific resistance it is important to use race-specific markers (Kim et al. 2015). Thomas and Webb (1982) reported that Pm-1 resistant gene of melon against race 1 fungus had dominant inheritance. In their study, powdery mildew resistant line PI78374 was used to develop $\mathrm{F}_{2}$ populations. Similarly, Pitrat (1991), by using the powdery mildew resistant line WMR29 and PI414723 reported that Pm- $W$ gene was resistant against the race 2 and $P m-X$ gene was resistant against race 1 . The author also reported that the $P m-X$ gene resistant against the race 1 was inherited as a single dominant factor. Perin et al. (2002) obtained 163 recombinant inbred lines (RILs) from a crossing of Védrantais $\times$ PI161375 of melon and the author developed a linkage map after phenotypic characterization and genotypic screening of those lines with 318 AFLP, IMAS, simple sequence repeat (SSR), RFLP markers. According to Perin et al. (2002) the resistant genes $P m-x$ (resistant against race 1) and $P m-w$ (resistant against race 2) were in the linkage groups (LG), LG II and LG V, respectively. Fukino et al. (2008) developed another linkage map and also analyzed the quantitative trait locus (QTL) with a population of recombinant inbred lines (RIL) between a resistant line AR5 and a susceptible line 'Earl's Favourite (Harukei 3)' for melon powdery mildew resistance. The authors used 167 markers including SSR, SCAR, CAPS markers. The authors reported that melon powdery mildew resistant QTL was located to LG II and LG XII in the linkage maps and the resistant line to powdery mildew race 1 could be selected by using SSR markers (Fukino et al. 2008). By analysis of the RILs between AR5 (syn. PMAR5) $\times$ Harukei 3 it was found that powdery mildew resistance-related genes of AR5 were located at LG II and LG XII in the QTL map and the identified two genes (Pm-II, Pm-XII) were probably involved in powdery mildew resistance (Fukino et al. 2008, personal communication with Dr. Fukino). In addition, AR5 was bred by several backcrossing with PMR5 and thus, the PMR5 and AR5 considered inheriting the same powdery mildew resistance gene. In the present study we confirmed that, an incidentally found powdery mildew fungus in Ibaraki region of Japan in 2009 was a new race. We than assessed a large number of commercially cultivated melon cultivars and lines against that race to select out resistant lines. Thereafter, we screened two different $F_{2}$ populations and one backcross populations obtained by mating between one resistant and one susceptible line. Finally, we screened 16 SSR markers and two polymorphic markers associated with resistant genes present in two independent LGs were used for genetic analysis of $F_{2}$ and backcross populations.

\section{MATERIALS AND METHODS}

\section{Plant materials}

Ten melon lines namely: Fuyu3, PMR45, WMR29, Edisto47, PI4144723, PMR5, PI124112, MR-1, ASL5, Ig1 were used for initial screening with newly identified $P$. xanthii race coupled with seven other reported races (Table 1). Later we screened a total of 42 melon germplasm including 19 commercial melon cultivars and some other melon inbred lines developed by the Plant Biotechnology Institute of Ibaraki Agricultural Center, Okayama University, United States Department of Agriculture and Institute National de la Recherche Agronomique, France (Table 2). We developed two different sets of $F_{2}$ populations and one backcross generation from the three different mating 
Table 1. Response of 10 melon cultigens to 7 reported races and a new race N5 of Podosphaera xanthii.

\begin{tabular}{|c|c|c|c|c|c|c|c|c|}
\hline \multirow{2}{*}{ Cultigen } & \multicolumn{7}{|c|}{ Race } & \multirow{2}{*}{$\frac{\text { New }}{\text { N5 }}$} \\
\hline & 1 & N1 & N2 & 5 & A & $\mathrm{S}$ & $\mathrm{O}$ & \\
\hline Fuyu3 & $\mathrm{S}$ & $\mathrm{S}$ & S & $\mathrm{S}$ & $\mathrm{S}$ & $\mathrm{S}$ & $\mathrm{S}$ & $\mathrm{S}$ \\
\hline PMR45 & $\mathrm{R}$ & $\mathrm{R}$ & S & $\mathrm{S}$ & $\mathrm{R}$ & $\mathrm{R}$ & $\mathrm{S}$ & $\mathrm{S}$ \\
\hline WMR29 & $\mathrm{R}$ & $\mathrm{R}$ & $\mathrm{R}$ & $\mathrm{S}$ & $\mathrm{R}$ & $\mathrm{R}$ & $\mathrm{S}$ & $\mathrm{S}$ \\
\hline Edisto47 & $\mathrm{R}$ & $\mathrm{R}$ & $\mathrm{R}$ & $\mathrm{S}$ & $\mathrm{R}$ & $\mathrm{R}$ & $\mathrm{S}$ & $\mathrm{S}$ \\
\hline PI414723 & $\mathrm{R}$ & $\mathrm{S}$ & $\mathrm{S}$ & $\mathrm{R}$ & $\mathrm{R}$ & $\mathrm{R}$ & $\mathrm{S}$ & I \\
\hline PMR5 & $\mathrm{R}$ & $\mathrm{R}$ & $\mathrm{R}$ & $\mathrm{R}$ & $\mathrm{R}$ & $\mathrm{R}$ & $\mathrm{S}$ & $\mathrm{R}$ \\
\hline PI124112 & $\mathrm{R}$ & $\mathrm{R}$ & $\mathrm{R}$ & $\mathrm{R}$ & $\mathrm{R}$ & $\mathrm{R}$ & $\mathrm{S}$ & $\mathrm{R}$ \\
\hline MR-1 & $\mathrm{R}$ & $\mathrm{R}$ & $\mathrm{R}$ & $\mathrm{R}$ & $\mathrm{R}$ & $\mathrm{R}$ & I & I \\
\hline ASL5 & $\mathrm{R}$ & $\mathrm{R}$ & $\mathrm{R}$ & $\mathrm{S}$ & $\mathrm{S}$ & $\mathrm{S}$ & $\mathrm{S}$ & $\mathrm{S}$ \\
\hline $\operatorname{Ig} 1$ & $\mathrm{R}$ & $\mathrm{R}$ & $\mathrm{R}$ & $\mathrm{R}$ & $\mathrm{R}$ & $\mathrm{S}$ & $\mathrm{R}$ & $\mathrm{S}$ \\
\hline
\end{tabular}

$\mathrm{R}$ : resistant, $\mathrm{S}$ : susceptible, I: Intermediate.

Table 2. Resistance and susceptibly of melon cultigens collected from different sources against the race N5 of Podosphaera xanthii.

\begin{tabular}{cll}
\hline \hline Race N5 & \multicolumn{1}{c}{ Cultigen } & \multicolumn{1}{c}{ Seed $^{-}$} \\
\hline Susceptible & Andes, Andes 3, Andes 5, Otome, Takami, Leina, Amus, Yuka, & Seed company, Japan \\
& Quincy, Lenon, Rupia red, Mikoto, Festa, Earl's Arena, Sonata & \\
& Syunjyu, Yellow king, Homerun star, Ginsen & \\
& P1, P2, P11, P14, P15, P18, P21, P22, P23, P25, P29, P32, L12 & PBI \\
& PMR45, Edisto47, WMR29, Ig1, Im5, Im9, It2 & USDA, INRA, Okayama University \\
Resistant & Mirano natsu I & Seed company, Japan \\
& P3 & PBI \\
& PMR5, PI124112 & USDA \\
\hline
\end{tabular}

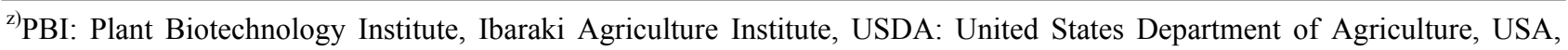
INRA: Institute National de la Recherche Agronomique, France.

combinations. The first set of $\mathrm{F}_{2}$ was obtained from a cross between CM17187 and PMR5, the second set of $\mathrm{F}_{2}$ was obtained from a cross between PMR45 and PMR5 and the $\mathrm{BC}_{1} \mathrm{~F}_{1}$ generation was obtained from a mating of PMR45×(PMR45 $\times$ PMR5). The first and second set of $F_{2}$ populations had 50 and 49 genotypes respectively, while the $\mathrm{BC}_{1} \mathrm{~F}_{1}$ generation had 94 genotypes.

\section{Pathogen materials}

A new race of $P$. xanthii causing powdery mildew disease against the resistant inbred line It 2 was identified in Ibaraki region in Japan in 2009 (data unpublished). Ten melon lines were initially tested with seven reported races coupled with the newly reported race (Table 1 ). The new race was designated as N5. All later pathogenicity tests were conducted against the new N5 race.

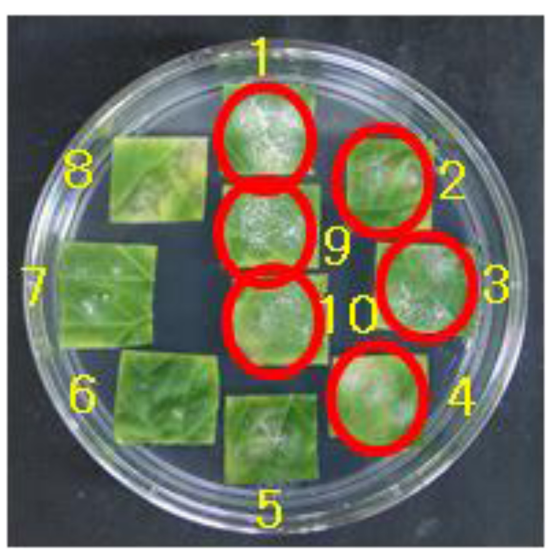

Fig. 1. Interaction of ten melon cultigens to race N5 in the leaf disc test 2 weeks after inoculation. Conidia growth was observed in susceptible cultigens indicated red circles. Cultigens 1 to 10 are respectively Fuyu3, PMR45, WMR29, Edisto47, PI414723, PMR5, PI124112, MR-1, ASL5, and Ig1. 


\section{Inoculation methods}

For the pathogenicity test, the leaf discs $(2 \times 2 \mathrm{~cm})$ of melon lines were inoculated with the fungal spores on the upper surface of the leaves by a tree stick as a modified method of Bardin et al. (1999) (Fig. 1). The resistant, susceptible and intermediate genotypes were selected based on the severity of the spread of fungal spores on the leaf discs at two weeks after inoculation. Genotypes were scored resistant, intermediate and susceptible when infected area of leaf discs were $0 \%-10 \%, 11 \%-30 \%$, and $31 \%-100 \%$, respectively.

\section{Selection of resistant lines and pathogenicity test of breeding populations}

To find out powdery mildew resistant genetic resources against the new fungal race, we inoculated leaf discs of a total of 42 melon germplasm including 19 commercial melon cultivars and some other melon inbred lines collected from three different sources (Table 2). The genotypes of $\mathrm{F}_{2}$ and backcross populations obtained from the selected parental combinations were also screened against the $\mathrm{N} 5$ race.

\section{Genetic analysis of resistance to melon powdery mildew new race}

Kim et al. (2015) published the resistant genes present in different races of powdery mildew fungus along with their position in three different groups, LG II, LG V, and LG XII. Combining our screening results with the location of resistant genes in relevant LGs (Kim et al. 2015), we developed genotypic configuration of different melon lines

Table 3. Resistant and susceptible interaction of genes located in linkage groups (LG) II and XII for parents and their $\mathrm{F}_{1}$ lines of melon against $\mathrm{N} 5$ fungal race.

\begin{tabular}{|c|c|c|c|}
\hline \multirow{2}{*}{ Line } & \multicolumn{2}{|c|}{ Resistant genes and locus of linkage map } & \multirow{2}{*}{ Response of race $\mathrm{N} 5^{2)}$} \\
\hline & LG II & LG XII & \\
\hline Fuyu3 & $p m-I I / p m-I I$ & $p m-X I I / p m-X I I$ & $\mathrm{~S}$ \\
\hline CM17187 & $p m-I I / p m-I I$ & $p m-X I I / p m-X I I$ & $\mathrm{~S}$ \\
\hline PMR45 & $P m-I I / P m-I I$ & $p m-X I I / p m-X I I$ & $\mathrm{~S}$ \\
\hline PMR5 & Pm-II/Pm-II & $P m-X I I / P m-X I I$ & $\mathrm{R}$ \\
\hline RIL31 & $p m-I I / p m-I I$ & $P m-X I I / P m-X I I$ & $\mathrm{R}$ \\
\hline$F_{1}$ line (Fuyu $3 \times$ RIL31) & $p m-I I / p m-I I$ & $P m-X I I / p m-X I I$ & $\mathrm{~S}$ \\
\hline $\mathrm{F}_{1}$ line $(\mathrm{CM} 17187 \times \mathrm{PMR} 5)$ & $P m-I I / p m-I I$ & $P m-X I I / p m-X I I$ & I \\
\hline$F_{1}$ line $(P M R 45 \times P M R 5)$ & Pm-II/Pm-II & $P m-X I I / p m-X I I$ & $\mathrm{R}$ \\
\hline $\mathrm{F}_{1}$ line $(\mathrm{PMR} 5 \times \mathrm{RIL} 31)$ & $P m-I I / p m-I I$ & $P m-X I I / P m-X I I$ & $\mathrm{R}$ \\
\hline
\end{tabular}

This interaction table has been developed comparing our screening results with mapping results of Fukino et al. (2008) and distribution information of resistant genes in different linkage groups (Kim et al. 2015).

${ }^{\mathrm{z})} \mathrm{R}$ : resistant, S: susceptible, I: intermediate.

Table 4. Resistant, intermediate and susceptible ( 3 classes) response of $50 \mathrm{~F}_{2}$ lines (CM17187×PMR5), $49 \mathrm{~F}_{2}$ lines (PMR45 $\times$ PMR5), and $94 \mathrm{BC}_{1} \mathrm{~F}_{1}$ lines (PMR45 $\times[\mathrm{PMR} 45 \times \mathrm{PMR} 5]$ ) against the race $\mathrm{N} 5$ of Podosphaera xanthii and the goodness of fit of 3 classes with expected ratios after $\chi^{2}$ test.

\begin{tabular}{lcccccc}
\hline \hline \multirow{2}{*}{$\mathrm{F}_{2}$ population } & \multicolumn{2}{c}{ Response to race N5 resistant $^{\mathrm{z}}$} & \multicolumn{3}{c}{$\chi^{2}$ test $^{\mathrm{y})}$} \\
\cline { 2 - 7 } & Resistant & Intermediate & Susceptible & $\chi^{2}$ & DF & $P$-value \\
\hline $\mathrm{F}_{2}$ lines $($ CM17187 $\times$ PMR5) & 18 & 12 & 20 & 0.13 & 2 & 0.93 \\
$\mathrm{~F}_{2}$ lines (PMR45 $\times$ PMR5) & 35 & 0 & 14 & 0.33 & 1 & 0.56 \\
$\mathrm{BC}_{1} \mathrm{~F}_{1}$ lines (PMR45 $\times[$ PMR45 $\times$ PMR5]) & 46 & 0 & 48 & 0.04 & 1 & 0.83 \\
\hline
\end{tabular}

${ }^{2)}$ The number showed phenotype by inoculation of powdery mildew race N5.

${ }^{y)}$ The data shows the results of $\chi^{2}$ test according to segregation ratio of resistance:intermediate:susceptibility $=3: 2: 3$ for $\mathrm{F}_{2}$ lines of CM17187 $\times$ PMR5, resistance:susceptibility $=3: 1$ for $F_{2}$ lines of PMR45 $\times$ PMR5, resistance:susceptibility=1:1 for BC1F1 lines of PMR45 $\times($ PMR45 $\times$ PMR5) . 
corresponding with their disease reaction against the N5 race (Table 3 ).

For the genetic analysis of resistance against the new N5 race, $\mathrm{F}_{1}$ of CM17187 (S)×PMR5 (R) and PMR45 (S) $\times$ PMR5 (R), their $\mathrm{F}_{2}$ populations and $\mathrm{BC}_{1} \mathrm{~F}_{1}$ lines of $(\mathrm{PMR} 45 \times[\mathrm{PMR} 45 \times \mathrm{PMR} 5])$ were inoculated and examined for the phenotypic resistance and the segregation ratio (Table 3). Chi-square test for goodness of fit with the expected ratio was conducted for each $F_{2}$ and $B_{1} F_{1}$ generations (Table 4).

\section{SSR marker analysis}

Polymerase chain reaction (PCR) amplification of susceptible line CM17187, PMR45, and resistant line PMR5 against powdery mildew race N5 were initially performed by using 16 SSR markers that have been published by Fukino et al. (2008) and Izumikawa et al. (2009) but among them six SSR markers were found polymorphic (Table 5). The amplified products were analyzed with fluorescent labels following the method of Yamamoto et al. (2007) and then detected by an ABI3130xl sequencer. The fragments size of polymorphic SSR markers between susceptible and resistant lines were determined (Table 5). In addition, by using the two selected SSR markers (CMN01-38 associated with LG XII and CMBR120 associated with LG II; Fukino et al. 2008), the $F_{2}$ populations of $\mathrm{CM} 17187 \times \mathrm{PMR} 5$ and the $F_{2}$ populations of PMR45 $\times$ PMR 5 were investigated to detect the pattern of polymorphism present therein. We then selected the SSR markers linked to N5 race by comparing SSR marker genotypes with corresponding phenotypes for resistance/susceptibility in response to race N5.

\section{RESULTS}

\section{Screening melon lines against $P$. xanthii}

We performed an inoculation test with a total of eight different races of $P$. xanthii including the collected new fungus race N5. Most of the melon lines were resistant against the previously reported six different races: race 1 , $\mathrm{N} 1, \mathrm{~N} 2,5, \mathrm{~A}$, and $\mathrm{S}$ (Table 1). However, against the race $\mathrm{O}$ only one line, Ig1, was found resistant (Table 1). Against the new race N5 the following six lines Fuyu3, PMR45, WMR29, Edisto47, ASL5, Ig1 were susceptible (Fig. 1, Table 1). Only two lines PMR5 and PI124112 had the resistant reactions against the new race (Fig. 1, Table 1). Two other lines MR-1 and PI414723 showed intermediate type of disease reactions in response to the N5 race (Fig. 1, Table 1).

\section{Screening melon commercial cultivars and lines against new $\mathrm{N} 5$ race}

In response to new $\mathrm{N} 5$ race, out of 42 melon genotypes (commercial cultivars and lines) only four genotypes (a commercial cultivar 'Mirano natsu I' and three bred line P3, PMR5, and PI124112) were found resistant (Table 2). All other 38 lines had susceptible disease reaction against this fungal race (Table 2).

\section{Genetic analysis of resistance to melon powdery mildew (P. xanthii) race N5}

The melon line CM17187 that was used in breeding program had susceptibility reaction against four reported races (race 5, A, S, and O) (data not shown) and also against the new N5 race (Fig. 2). We, therefore, used CM17187 in the genetic analysis as it was presumed that this line did not

Table 5. Polymorphism of PCR fragments obtained by using 6 SSR marker located in LG XII in susceptible lines CM17187, PMR45, and resistant line PMR5 of melon.

\begin{tabular}{lcccccc}
\hline \hline \multirow{2}{*}{ Line } & \multicolumn{7}{c}{ Marker $(\mathrm{bp})$} \\
\cline { 2 - 7 } & CMN22-45 & CMN01-38 & CMBR150 & CMBR14 & CMGAN80 & CMAGN32 \\
\hline PMR45 & 269 & 225 & 283 & 175 & 171 & 191 \\
CM17187 & 269 & 215 & 279 & 175 & 171 & 191 \\
PMR5 & 264 & 219 & 281 & 158 & 183 & 193 \\
\hline
\end{tabular}

PCR: polymerase chain reaction, SSR: simple sequence repeat, LG: linkage group. 
inherit any of the following resistant genes: $P m-I I$ and Pm-XII similar to PMR5. A further inoculation test by race $\mathrm{N} 5$ fungus resulted in susceptible reaction for following three lines: Fuyu3, CM17187 (pm-II homo, pm-XII homo) and PMR45 (Pm-II homo, pm-XII homo) but RIL31 (pm-II homo, Pm-XII homo) and PMR5 (Pm-II homo, Pm-XII homo) resulted in resistant reaction (Fig. 2, Table 3). $F_{1}$ line (Pm-II hetero, Pm-XII hetero) of CM17187×PMR5 had intermediate type of disease reaction between resistant and susceptible types (Fig. 2). The first set of $F_{2}$ populations obtained by selfing of the $\mathrm{F}_{1}$ line of CM17187×PMR5 were inoculated with race $\mathrm{N} 5$ fungus. The disease response of 50
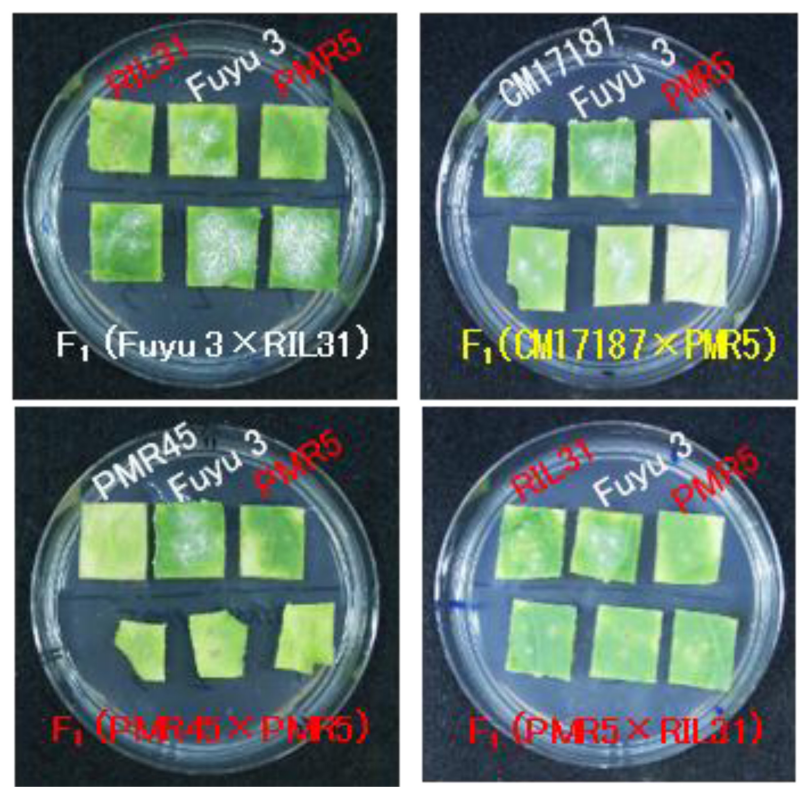

Fig. 2. Resistant (red letters), susceptible (white letters), and intermediate (yellow letters) disease reactions of melon lines and their $\mathrm{F}_{1} \mathrm{~s}$ against the race $\mathrm{N} 5$ of Podosphaera xanthii.
$\mathrm{F}_{2}$ populations against the race $\mathrm{N} 5$ fungus separated them into resistant:intermediate: susceptible $=18: 12: 20 \fallingdotseq 3: 2: 3$ ratios for a $\chi^{2}$ test (Table 4 ). The frequency of the three different phenotypes fitted well with the presumed segregation ratio 3:2:3 but not with 1:2:1 (Table 4).

$\mathrm{F}_{1}$ line (pm-II homo, Pm-XII hetero) of Fuyu $3 \times$ RIL31 showed susceptibility, $\mathrm{F}_{1}$ line ( $P m-I I$ homo, $P m-X I I$ hetero) of PMR45 $\times$ PMR5 showed resistance and $\mathrm{F}_{1}$ line (Pm-II hetero, Pm-XII homo) of PMR5 $\times$ RIL31 showed strong resistance against the race N5 (Fig. 2, Table 3). The second set of $F_{2}$ populations having 49 lines obtained from the selfing of $\mathrm{F}_{1}$ (Pm-II homo, P $m$-XII hetero) of PMR45 $\times$ PMR5 were separated into resistant:susceptible $=34: 14 \fallingdotseq 3: 1$ ratio against race $\mathrm{N} 5$ fungus for a $\chi^{2}$ test (Table 4 ). The frequency of the two different phenotypes fitted well with the expected segregation ratio 3:1 (Table 4).

In addition, $94 \mathrm{BC}_{1} \mathrm{~F}_{1}$ populations ( $P m-I I$ homo, $P m-X I I$ hetero or without) of PMR $45 \times($ PMR $45 \times$ PMR5) were separated into resistant:susceptible $=46: 48 \fallingdotseq 1: 1$ for a $\chi^{2}$ test (Table 4). The frequency of the two different phenotypes fitted well with the segregation ratio 1:1 (Table 4).

\section{Selection of DNA markers for the powdery mildew resistant gene of race $\mathrm{N} 5$ in melon}

We tested 16 SSR markers for their polymorphism for Pm-XII gene located in LG XII in response to race N5. PCR products obtained by six markers were polymorphic between the susceptible lines CM17187, PMR45 and resistant line PMR5 of melon (Table 5). SSR genotyping revealed that melon line was resistant because of the presence of Pm-XII homo gene in LG XII irrespective of the status of another locus located in LG II (Table 3, Table

Table 6. Distribution of $50 \mathrm{~F}_{2}$ population $(\mathrm{CM} 17187 \times \mathrm{PMR} 5)$ to three different categories (resistant homo, hetero, and susceptible homo against N5 fungal race) according to SSR genotyping by two markers.

\begin{tabular}{|c|c|c|c|c|}
\hline \multirow[b]{2}{*}{ SSR marker } & \multirow[b]{2}{*}{ Marker type } & \multicolumn{3}{|c|}{ CMBR120 (LG II) } \\
\hline & & $\begin{array}{l}\text { Resistant homo } \\
\text { (196 bp) }\end{array}$ & $\begin{array}{c}\text { Hetero } \\
(184 / 196 \mathrm{bp})\end{array}$ & $\begin{array}{l}\text { Susceptible homo } \\
\text { (184 bp) }\end{array}$ \\
\hline \multirow[t]{3}{*}{ CMN01-38 (LG XII) } & Resistant homo (219 bp) & Resistant $(2 / 2)^{\mathrm{z})}$ & Resistant (4/4) & Resistant (3/3) \\
\hline & Hetero $(215 / 219$ bp) & Resistant (7/7) & Intermediate $(12 / 18)$ & Susceptible $(4 / 5)$ \\
\hline & Susceptible homo (215 bp) & Susceptible $(1 / 1)$ & Susceptible $(3 / 6)$ & Susceptible $(3 / 4)$ \\
\hline
\end{tabular}

\footnotetext{
${ }^{z)}$ The number of the matched line of genotype with phenotype for race N5/the number of genotyping line.
}

SSR: simple sequence repeat, LG: linkage group. 
Table 7. Distribution of $49 \mathrm{~F}_{2}$ population (PMR45×PMR5) to three different categories (resistant homo, hetero, and susceptible homo against N5 fungal race) according to SSR genotyping by two markers.

\begin{tabular}{lllcc}
\hline \hline \multirow{2}{*}{ Marker } & \multicolumn{1}{c}{ Marker type } & \multicolumn{3}{c}{ CMBR120 (LG II) } \\
\cline { 3 - 5 } & & \multicolumn{1}{c}{$\begin{array}{c}\text { Resistant homo } \\
(196 \mathrm{bp})\end{array}$} & Hetero & Susceptible homo \\
\hline CMN01-38 (LG XII) & Resistant homo (219 bp) & Resistant $(11 / 11)^{\mathrm{z})}$ & $-{ }^{\mathrm{y})}$ & - \\
& Hetero (219/225 bp) & Resistant $(24 / 27)$ & - & - \\
& Susceptible homo (225 bp) & Susceptible $(11 / 11)$ & - & - \\
\hline
\end{tabular}

${ }^{2)}$ The number of the matched line of genotype with phenotype for race N5/the number of genotyping line.

y) _- sign indicates absence of heterozygous or homozygous susceptible allele. The two parents are homozygous for resistant allele (located in LG II) and therefore $F_{2}$ populations of PMR45 $\times$ PMR5 were neither heterozygous nor homozygous susceptible.

LG: linkage group.

6). SSR genotyping further revealed that $P m-I I$ homo gene present in LG II was required for the resistance reaction against the race N5, when in another LG (LG XII) was hetero Pm-XII/pm-XII (Table 3, Table 6). When Pm-II/pm-II hetero gene was present in LG II then another gene present in LG XII was in homozygous dominant for a resistant reaction (Table 3, Table 6). Thus the two SSR markers associated with resistance against the race $\mathrm{N} 5$ were selected from LG II (CMBR120) and LG XII (CMN01-38) (Table 6). The $F_{2}$ populations of $C M 17187 \times \mathrm{PMR} 5$ (consists of 50 offspring having 18 resistant lines, 12 intermediate lines, and 20 susceptible lines) and PMR45 $\times$ PMR5 (consists of 35 resistance lines and 14 susceptible lines) were assessed with two selected SSR markers CMN01-38 (linked with LG XII) and CMBR120 (linked with LG II) (Table 6, 7). The SSR genotypes of two markers, CMBR120 and CMN01-38, matched highly with resistant or susceptible phenotypes against the race N5 fungus. Out $50 \quad \mathrm{~F}_{2}$ populations of CM17187 $\times$ PMR5, 78\% SSR genotypes matched with expected phenotypes (either resistant or susceptible types) and out of $49 \mathrm{~F}_{2}$ populations of PMR 45 $\times$ PMR5 94\% SSR genotypes matched with expected phenotypes (Table 6,7).

\section{DISCUSSION}

Background of this study lay on an incidental observation in the cultivated melon fields of Ibaraki region of
Japan during summer season of 2009. In that season, powdery mildew fungi were collected in Ibaraki prefecture of Japan from the cultivated fields of melon. The inbred line of melon It2 was screened against seven races (race 1, N1, N2, 5, A, S, O) of $P$. xanthii and was found to be resistant against all seven races (data unpublished). But that inbred line we found susceptible against another race (that was the focus of this study) which was virulent to that resistant line It2. Afterwards, the new powdery mildew fungus virulent to It 2 inbred line was inoculated to leaf disc of the selected melon lines. We then screened a collection of commercial melon cultivars and lines to select out resistant (R) and susceptible (S) genotypes. Later we produced several $F_{1}, F_{2}$ and back-cross populations for genetic analysis and used molecular markers to analyze their resistance response against the new fungal race.

\section{Confirmation of new fungal race}

The response of 10 melon lines against the new fungus race N5 was different from previously reported seven races by Izumikawa et al. (2008). The results thus confirmed that the N5 race was a new fungal race of $P$. xanthii. Disease response of 10 lines against the N5 race had partial similarity with race 5 although the line $\operatorname{Ig} 1$ had a resistance to the race 5 , but it showed susceptibility to the new race. Thus, it could be speculated that the new 'race N5' is a mutant of the race 5 (Table 1). Two lines resistant against the N5 race, PMR5, and PI124112, were used in genetic analysis. We recommend that these two lines could be used 
for transferring resistance to other commercially important melon lines using them as a parent in any future breeding program. Also these two lines could be used for marker development and linkage map development.

\section{Epistatic gene interaction is present}

SSR genotyping revealed that interaction between genes located in two different LGs was required for resistant reactions of the melon lines against the $\mathrm{N} 5$ race (Table 6, 7). For the $F_{2}$ populations of CM17187×PMR5, a resistant phenotype was observed when gene present in LG XII was in homozygous dominant state (Table 4). When gene present in LG XII was heterozygous then another gene present in LG II was required to be in homozygous dominant state for their resistant reactions (Table 4). When the genes in two different LGs were in heterozygous state an 'intermediate type' disease response was observed (Table 6). Absence of dominant gene allele in LG XII always resulted in susceptibility irrespective of the status of the gene present in LG II (Table 6). Absence of any dominant gene allele in LG II group in presence of one dominate gene allele in LG XII also resulted in susceptible disease reaction (Table 6). Since expression of the gene located in locus LG II and LG XII were dependent on each other therefore it could be commented that an epistatic gene interaction was present in favor of the powdery mildew resistance in melon. In the second set of $\mathrm{F}_{2}$ populations of PMR 45 $\times$ PMR5 susceptible disease reactions was observed when gene present in LG XII was in homozygous recessive state in presence of homozygous dominant status of another locus present in LG II (Table 7). The results indicated that at least one dominant allele is required in $\mathrm{LG}$ XII in presence of homozygous dominant status of LG II locus (Table 7). In a recent study, differential expression of $14 M L O$ genes have been reported in the same melon line in response to seven different fungal races of $P$. xanthii (Howlader et al. 2016) which suggested possible existence of inter-genic gene interaction.

\section{SSR genotyping confirmed phenotypic ratios}

The two selected SSR markers (CMBR120, CMN01-38) which were able to separate the resistant and susceptible genotypes against N5 race were located in LG II and LG
XII. For different other races, resistant QTL were reported to be located in LG II, LG V, and LG XII (Fukino et al. 2008; Izumikawa et al. 2009; Kim et al. 2015). Comparing our results with that of previous studies it can be commented that the resistant genes for powdery mildew race $\mathrm{N} 5$ were located in the same or near the other resistant genes of powdery mildew against other different races, for example: Pm-XII of AR5 and Pm-y of VA435 were located in LG XII (Pitrat 1991; Fukino et al. 2008). By using the SSR markers, the resistant lines against the powdery mildew N5 race were selected in high accuracy between $78 \%$ and $94 \%$ from the $F_{2}$ populations (Table 6, 7). Furthermore, these markers could be used for selecting resistant line and cultivars with unknown disease response against the race $\mathrm{N} 5$.

\section{ACKNOWLEDGEMENTS}

This research was supported by the Export Promotion Technology Development Program (Grant No. 31206505-4-HD030) and Golden Seed Project (Center for Horticultural Seed Development, No. 213003-04-4-SB110) Ministry of Agriculture, Food and Rural Affairs (MAFRA), Ministry of Oceans and Fisheries (MOF), Rural Development Administration (RDA) and Korea Forest Service (KFS). The authors thank Dr. Nobuko Fukino for her kind comments.

\section{REFERENCES}

Bardin M, Dogimont C, Nicot P, Pitrat M. 1999. Genetic analysis of resistance of melon line PI 124112 to sphaerotheca fuliginea and erysiphe cichoracearum studied in recombinant inbred lines. Proceedings of the 1st International Symposium on Cucurbits. Acta Hortic. 492: 163-168.

Cohen Y, Eyal H, Thomas CE. 1984. Stabilizing resistance in Cucumis melo against downy and powdery mildews in Israel and the USA (abstract). Phytopathology 74: 829.

Epinat C, Pitrat M, Bertrand F. 1992. Genetic analysis of resistance of five melon lines to powdery mildews. Euphytica 65: 135-144. 
Fukino N, Ohara T, Monforte AJ, Sugiyama M, Sakata Y, Kunihisa M, et al. 2008. Identification of QTLs for resistance to powdery mildew and SSR markers diagnostic for powdery mildew resistance genes in melon (Cucumis melo L.). Theor. Appl. Genet. 118: 165-175.

Hosoya K, Narisawa K, Pitrat M, Ezura H. 1999. Race identif cation in powdery mildew (Sphaerotheca fuliginea) on melon (Cucumis melo L.) in Japan. Plant Breed. 118: 259-262.

Howlader J, Kim HT, Park JI, Ahmed NU, Robin AHK, Jung HJ, et al. 2016. Expression profiling of MLO family genes under Podosphaera xanthii infection and exogenous application of phytohormones in Cucumis melo L. J. Life Sci. 26: 419-430.

Izumikawa Y, Kuzuya M, Takazusu Y, Miyagi M. 2008. Occurrence of several pathogenic strains of melon powdery mildew with different host-specificity and search for melon breeding materials resistant to these strains. Proc. of The 114th Annual Meeting of the Japanese Society of Breeding. Shiga, Japan. 10: 196.

Izumikawa Y, Fukino N, Kuzuya M, Miyagi M. 2009. Phenotypic analysis of powdery mildew resistant gene originated from commercial cultivar of melon. 1 . Resistant gene linked with SSR marker, CMBR8. Hort. Res. (Jpn.) 8: 173.

Jagger IC, Whitaker TW, Porter DR. 1938. A new biologic form of powdery mildew on Muskmelons in the Imperial Valley of California. Plant Dis. Reptr. 22: 275-276.

Kim HT, Park JI, Ishikawa T, Kuzuya M, Horii M, Yashiro K, et al. 2015. Development of molecular marker to select resistant lines and to differentiate the races related to powdery mildew in melon (Cucumis melo L.). J. Plant Biotechnol. 42: 284-289.

Kuzuya M, Yashiro K, Tomita K. 2004. Melon breeding for resistance to powdery mildew in respect to its races. Proc. Vege. Tea Sci. 1: 39-43.

McCreight JD. 2006. Melon-powdery mildew interactions reveal variation in melon cultigens and Podosphaera xanthii races 1 and 2. J. Am. Soc. Hort. Sci. 131: 59-65.

McCreight JD, Pitrat M, Thomas CE, Kishaba AN, Bohn GW. 1987. Powdery mildew resistance genes in muskmelon. J. Am. Soc. Hort. Sci. 112: 156-160.

Mohamed YE, Bardin M, Nicol PC, Pitrat M. 1995. Causal agents of powdery mildew of cucurbits in Sudan. Plant Dis. 79: 634-636.

Périn C, Hagen S, De Conto V, Katzir N, Danin-Poleg Y, Portnoy V, et al. 2002. A reference map of Cucumis melo based on two recombinant inbred line populations. Theor. Appl. Genet. 104: 1017-1034.

Pitrat M. 1991. Linkage groups in Cucumis melo L. J. Hered. 82: 406-411.

Pryor DE, Whitaker TW, Davis GN. 1946. The development of powdery mildew resistant cantaloupes. Proceed. Am. Soc. Hort. Sci. 47: 347-356.

Thomas CE, Webb RE. 1982. 'Cinco' muskmelon. Hort. Sci. 17: 684-685.

Yamamoto T, Kimura T, Terakami S, Nishitani C, Sawamura $\mathrm{Y}$, Saito T, et al. 2007. Integrated reference genetic inkage maps of pear based on SSR and AFLP markers. Breed. Sci. 57: 321-329. 